\title{
Longwave indirect effect of mineral dusts on ice clouds
}

\author{
Q. Min and R. Li \\ Atmospheric Sciences Research Center, State University of New York, Albany, NY 12203, USA
}

Received: 4 November 2009 - Published in Atmos. Chem. Phys. Discuss.: 15 January 2010

Revised: 3 August 2010 - Accepted: 11 August 2010 - Published: 23 August 2010

\begin{abstract}
In addition to microphysical changes in clouds, changes in nucleation processes of ice cloud due to aerosols would result in substantial changes in cloud top temperature as mildly supercooled clouds are glaciated through heterogenous nucleation processes. Measurements from multiple sensors on multiple observing platforms over the Atlantic Ocean show that the cloud effective temperature increases with mineral dust loading with a slope of $+3.06^{\circ} \mathrm{C}$ per unit aerosol optical depth. The macrophysical changes in ice cloud top distributions as a consequence of mineral dust-cloud interaction exert a strong cooling effect (up to $16 \mathrm{Wm}^{-2}$ ) of thermal infrared radiation on cloud systems. Induced changes of ice particle size by mineral dusts influence cloud emissivity and play a minor role in modulating the outgoing longwave radiation for optically thin ice clouds. Such a strong cooling forcing of thermal infrared radiation would have significant impacts on cloud systems and subsequently on climate.
\end{abstract}

\section{Introduction}

Changes in aerosols can modulate the distribution of radiative heating indirectly by altering the cloud radiative properties, precipitation efficiency, and cloud evolution. Previous studies of aerosol indirect effects have emphasized their potential contributions to planetary cooling, through microphysical processes due to the greater activation of cloud droplets, i.e., "the cloud albedo effect" (Twomey, 1977; Forster et al., 2007). Microphysical changes in clouds also exert thermal radiative forcing by altering cloud emissivity, particularly in arctic region (Lubin and Vogelmann, 2006; Garrett and Zhao, 2006). Most research so far, however, has dealt with warm, liquid clouds.

Correspondence to: $\mathrm{Q}$. Min

(min@asrc.cestm.albany.edu)
Laboratory experiments, in-situ measurements, ground based lidar, and satellite remote sensing studies have shown that some aerosols - mineral dusts in particular are effective ice nuclei (IN). The main effect of efficient IN is to lower the threshold temperature and relative humidity for ice cloud formation, producing more ice particles at warmer temperatures and lower supersaturation (Schaller and Fukuta, 1979; Levi and Rosenfeld, 1996; Sassen, 2002, 2005; Demott et al., 2003a,b; Hung et al., 2003; Sassen et al., 2003; Chylek et al., 2006; Huang et al., 2006; Ou et al., 2009; Min et al., 2009). In addition to microphysical changes in clouds, changes in nucleation processes in ice cloud due to aerosols may result in substantial changes of cloud top distribution, since mildly supercooled clouds are glaciated at unusually warm temperatures through heterogeneous nucleation. The macrophysical changes in clouds with respect to atmospheric temperature would exert a strong thermal infrared radiative forcing on cloud systems and subsequently on climate. Such a radiation pathway of aerosol indirect effects, however, has not yet been investigated (Forster et al. 2007; Denman et al. 2007). In this study, we utilize multiple sensors on multiple observing platforms to study impacts of mineral dust on ice cloud microphysical and macrophysical properties, with a focus on the associated thermal infrared radiative forcing of cloud systems over the Atlantic Ocean.

\section{Measurements and methodology}

A trans-Atlantic Saharan dust outbreak that occurred 1-7 March 2004 forms the background to this study (Nalii et al 2006; Morris et al 2006; Min et al 2009). The mineral dust interacted with cloud systems as the dust layer travelled across the tropical eastern Atlantic Ocean. As indicated by Meteosat-8 Red/Green/Blue composite images (Fig. 1a, the case at 13:45 UTC, 7 March 2004) and retrievals from the Moderate Resolution Imaging Spectroradiometer (MODIS)

Published by Copernicus Publications on behalf of the European Geosciences Union. 

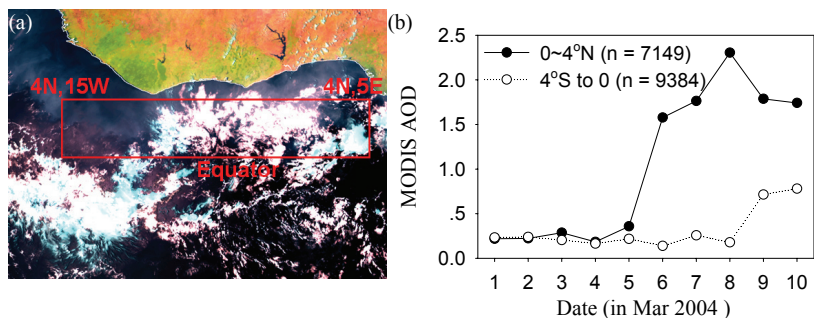

Fig. 1. (a) Meteosat- 8 RGB composite image over the northeast Atlantic Ocean at 13:42 UTC on 7 March 2004. (b) Time series of domain averaged aerosol optical depth derived from MODIS during 1 to 10 March 2004 for the domains of $\left(0 \sim 4^{\circ} \mathrm{N}, 15^{\circ} \mathrm{W} \sim 5^{\circ} \mathrm{E}\right)$ and $\left(0^{\circ} \sim 4^{\circ} \mathrm{S}, 15^{\circ} \mathrm{W} \sim 5^{\circ} \mathrm{E}\right)$

on Aqua, the mean aerosol optical depths were near a constant of 0.19 between 1 and 4 March 2004 and increased to about 1.85 between 6 and 10 March 2004 in a domain from $4^{\circ} \mathrm{N}$ to $0^{\circ} \mathrm{N}$ and from $10^{\circ} \mathrm{W}$ to $5^{\circ} \mathrm{E}$ (Fig. 1b). This event was also identified as a typical dust event by the MODIS Rapid Response Project and the NOAA Operational Significant Event Imagery team.

To assess the indirect effect of thermal radiation directly, we used the Clouds and the Earth's Radiant Energy System (CERES) Single Scanner Footprint (SSF) dataset, in which CERES radiation measurements are combined with cloud properties from a high-resolution imager of MODIS within the footprint of CERES [Geier et al., 2003]. Cloud optical properties are retrieved for both daytime and nighttime overpasses, with a coarse resolution of $20 \mathrm{~km}$. The nighttime retrievals are based only on infrared channels, and may have large uncertainties. Since the focus of this study is the contrasts of cloud and radiation between dust and dustfree conditions, some uncertainties would have limited impact on the systematic differences between the two conditions. The CERES SSF dataset provides cloud effective temperature (CET), which is the equivalent blackbody temperature of the cloud as seen from above. The temperature within a cloud generally decreases with increasing (decreasing) height (pressure). An integration of radiation over the cloud physical thickness defines the effective temperature. The effective temperature corresponds to some location between the cloud base and the cloud top. Due to the relatively large footprint of CERES pixels, cloud field inhomogeneity may introduce large uncertainty of inferred cloud properties. To minimize the impacts of cloud field inhomogeneity we only analyze pixels of CERES where a single layer cloud occupied more than $90 \%$ of the footprint, resulting in 3505 ice cloud samples from CERES FM3 and FM4 sensors during the event.

Cloud evolution can be affected profoundly not only by aerosols but also by large scale dynamics and thermodynamics. For this reason, several additional datasets have been used, including aerosol optical depth and dynamical and ther- modynamical parameters. As aerosol optical depth (AOD) is derived from Aqua MODIS measurements in the vicinity of cloudy pixels with $1^{\circ} \times 1^{\circ}$ resolution (MYD08, Hubanks et al., 2008), we projected other datasets onto the same $1^{\circ} \times 1^{\circ}$ grid and paired all associated data in the box. For example, for a given CERES SSF retrievals, if the AOD retrieval within the box was available, we assigned the AOD value to the box; if not, we used the AOD value averaged from the surrounding eight $1^{\circ} \times 1^{\circ}$ boxes. Otherwise, this box was excluded from analysis. By doing so, a total of 2090 pairs were valid, consisting of $\sim 60 \%$ of the total SSF samples. If using AOD information from the collocated $1^{\circ} \times 1^{\circ}$ boxes alone, which represents a more strict collocation constraint, only 666 pairs ( $\sim 22 \%$ of the total) were obtained. We also utilized the sea surface temperature (SST) and column integrated water vapor path (WVP) retrieved from Aqua Advanced Microwave Scanning Radiometer - EOS (AMSR-E), and the NCEP FNL Operational Global Analysis data at 12:00 UTC (close to satellite overpasses) to investigate possible impacts of large scale dynamics on cloud properties.

\section{Results}

Cloud microphysical properties intrinsically link to cloud macrophysical characteristics through dynamic and thermodynamic processes. As shown in Fig. 2a, there is a negative correlation $\left(R^{2}=0.19\right.$, above $99 \%$ confidence level, assuming independent, Gaussian-distributed variables) between the cloud effective temperature (CET) and the cloud ice water path (IWP). As thick ice clouds (large IWP) are formed under favorable dynamic and thermodynamic conditions, they grow to higher altitudes with colder cloud effective temperatures. The slope for all paired data is $-9.79{ }^{\circ} \mathrm{C}$ per unit $\log _{10}$ IWP. With the strict collocation threshold leads to a consistent result: slope of $-9.29^{\circ} \mathrm{C}$ per unit $\ln (\mathrm{IWP})$ with correlation efficient $\left(R^{2}\right)$ of 0.17 . More interestingly, as shown in Fig. 2b, the CET correlates with the ambient aerosol optical depth with a slope of $+3.06{ }^{\circ} \mathrm{C}$ per unit AOD. The correlation coefficient $\left(R^{2}\right)$ is 0.08 with the confidence level above $99 \%$. Particularly, the minimum cloud effective temperature appears to increase with AOD. This indicates that ice clouds tend to be formed at warmer effective temperature (lower altitude) with an increase of aerosol loading. It is worth noting that using data pairs under the strict collocation threshold, the correlation efficient $\left(R^{2}\right)$ increases to 0.11 with a larger slope of $+3.96^{\circ} \mathrm{C}$ per unit AOD. More importantly, there is no coherent correlation between AOD and IWP $\left(R^{2}=0.0018\right)$. Because thick ice cloud (large IWP) generally form in strong convection with large amounts of water vapour, IWP, to some extent, is an indicator of dynamical and thermodynamical conditions. This suggests that the observed tendency of cloud effective temperature with AOD can not be attributed simply to changes in cloud dynamical and thermodynamical conditions. 

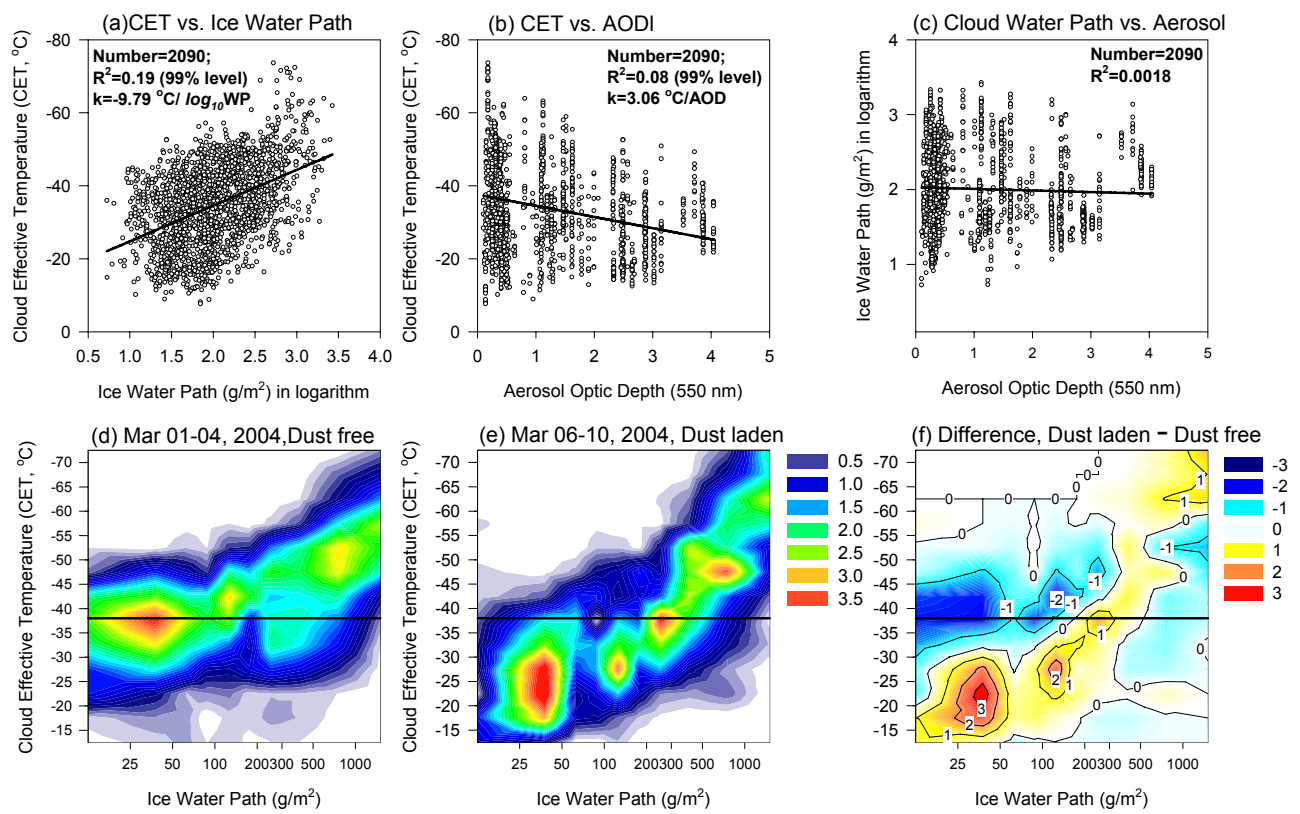

Fig. 2. Upper panel: correlations between (a) ice cloud effective temperature and ice water path; (b) ice cloud effective temperature and environmental aerosol optic depth; (c) ice water path and environmental aerosol optical depth. Lower panel: Joint probability density function (JPDF) of ice cloud effective temperature and ice water path during (d) dust-free period of 1-4 March 2004 and (e) heavy dust-laden period of 6-10 March 2004. The associate difference of JPDF between them is shown in (f).

The above analysis suggests that mineral dust plays a role in regulating cloud top height. However, ice clouds are mainly determined by dynamics and thermodynamics. To differentiate the indirect effect of mineral dust from dynamical influences, we segregated all samples into two groups based on dust loading conditions: the dust-laden period (DS, 6-10 March 2004) and the dust-free period (DF, 1-4 March 2004). The data on 5 March 2004, as a transit/buffering day, was excluded to ensure distinct dust aerosol loading between the two groups. The difference of ice cloud properties and outgoing longwave radiation (OLR) flux between the two are compared statistically and related to the associated dynamic and thermodynamic conditions, in terms of joint probability density distribution (joint PDF).

The cloud effective temperature generally decreases with ice water path for both periods, shown in Fig. 2d and e, which is consistent with Fig. 2a. However, the joint PDF of CET and IWP in the DS period shows a systematic shift compared to that in the DF period, as shown in the difference of joint PDF between the DS and DF periods for each IWP bin (Fig. 2f). More ice clouds with IWP $<300 \mathrm{~g} / \mathrm{m}^{2} \mathrm{oc}-$ curred at warmer temperatures $\left(\mathrm{CET}>-30^{\circ} \mathrm{C}\right)$ in the DS period than in the DF period. On the other hand, thick ice clouds with IWP $>300 \mathrm{~g} / \mathrm{m}^{2}$ in the DS period tend to have colder cloud effective temperature than their DF counterparts. Those thick ice clouds, a few in number $(\sim 15 \%$ of total cloud samples), may be associated directly with deep convective cells. Higher cloud top for those thick clouds in the DS period implies that convection strengths for those deep convective cells were stronger than in the DF period, or the background dynamic conditions were favorable for convection in the DS period. It suggests that dynamic factors may not be the cause of the observed lower cloud top heights (warmer cloud effective temperatures) in the DS period for the majority of samples of ice clouds with IWP less than $300 \mathrm{~g} \mathrm{~m}^{-2}$, which were formed either from weak deep convections or from the outflow of deep convective clouds. Assuming dynamical conditions were comparable in both periods (see below), the observed difference of CET for thick ice clouds may suggest that dust invigorate the convection (van den Heever et al., 2006; Rosenfeld et al., 2008; Gong et al., 2010), resulting in higher cloud tops. Given limited samples of those thick ice clouds in our current study, further robust statistical analysis is warranted to draw a solid conclusion on the dust induced convection invigoration process.

To further investigate possible impacts of large scale dynamics on cloud properties, we used collocated SST and WVP from AMSR-E observations, Convective Available Potential Energy (CAPE), vertical velocity at $500 \mathrm{hPa}, \mathrm{W}_{500 \mathrm{hpa}}$, relative humidity at $500 \mathrm{hPa}, \mathrm{H}_{500 \mathrm{hpa}}$, and temperature difference between 850 and $500 \mathrm{hPa}, \Delta T 8_{850--500 \mathrm{hpa}}$, from NCEP reanalysis as indicators of dynamics. We focused on the difference of the joint PDFs of CET with each dynamical indicator between the DS and DF periods for the majority of samples of ice clouds that had IWP less than $300 \mathrm{~g} \mathrm{~m}^{-2}$. As shown in Fig. 3, in which joint PDFs are normalized in each bin, more ice clouds occurred at warmer temperatures in the DS period than in the DF period. Such characteristics exist 
(a) SST

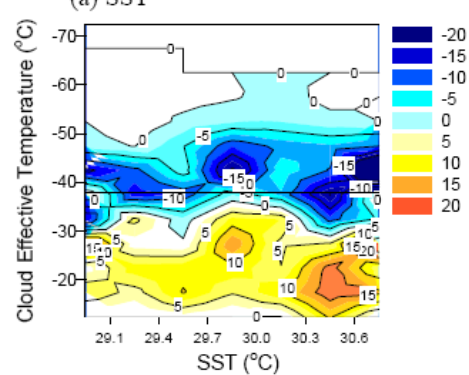

(d) CAPE

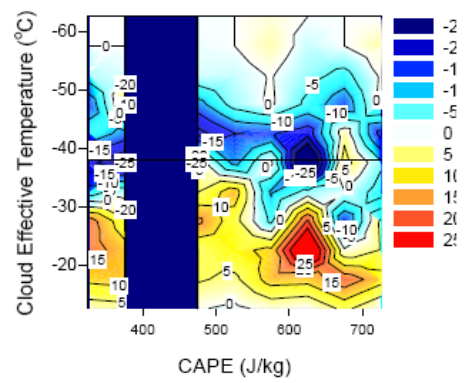

(b) Column water vapor

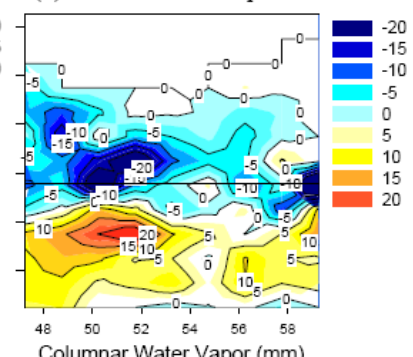

Columar Water Vapor (mm)

(e) T850-T500

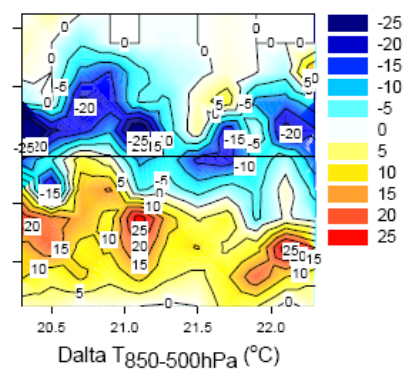

(c) Updraft velocity (500hpa)

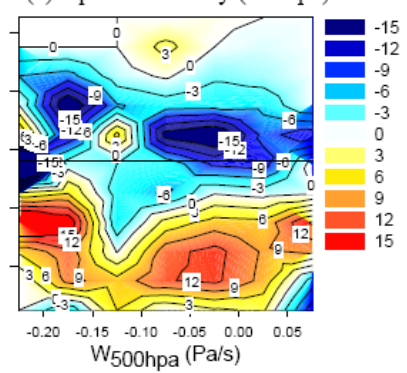

(f) Relative humidity (500hpa)

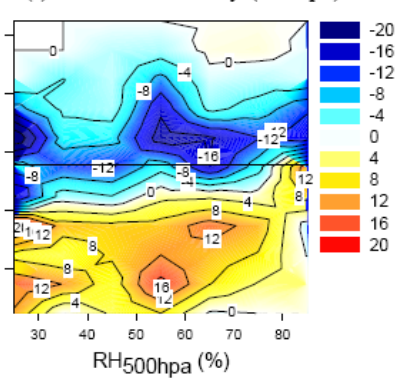

Fig. 3. The difference of probability density functions (PDFs) of ice cloud effective temperature between dust-free and dust-laden conditions with given (a) sea surface temperature; (b) column integrated water vapor; (c) mid-level updraft velocity (500hPa); (d) convection available potential energy; (e) temperature difference between 850 and $500 \mathrm{hPa}$; and (f) mid level relative humidity $(500 \mathrm{hPa})$.

systematically cross the range of each dynamical indicator. Those results suggest that the dynamical indicators and their associated dynamical and thermodynamical processes may not be the cause of the observed CET difference between the DF and DS periods.

Model studies have indicated that the numbers of available IN at lower ice supersaturations are critical in determining the dominant ice-formation process (DeMott et al. 2003a). Mineral dusts are good ice nuclei that help initiate ice cloud formation at modest supersaturartion and temperatures (DeMott 2003b; Sassen et al. 2003; Sassen 2005). Mineral dusts-induced ice clouds have been observed at a warm temperature of $-15^{\circ} \mathrm{C}$, abnormally warmer than normal ice clouds forming via homogeneous nucleation in remote Alaska (Sassen 2002). As indicated by Min et al. (2009), more IN introduced by large concentrations of mineral dusts may produce more ice particles at warmer temperatures. Additionally, water vapour depletion as a consequence of mineral dust heterogeneous nucleation may reduce the peak supersaturation at higher altitudes, which limits the onset of the homogeneous nucleation process (DeMott et al. 1998; Min et al., 2009). It is plausible that the consequence of heterogeneous nucleation of mineral dust shifts the occurrence distribution of ice clouds to a lower altitude (a warmer temperature).

Decreases in cloud top height, occurrence frequency, fractional amount, or increase in emissivity can increase the outgoing longwave radiation (OLR), which cools the atmosphere. As shown in Fig. 4, the cloud effective tempera- ture decreased with cloud ice water path in both daytime and nighttime, while nighttime ice clouds were formed at colder effective temperatures than daytime ice clouds. Clouds in the DS period clearly had warmer effective temperature than that in the DF period for both daytime and nighttime. The differences of the mean CET between the two periods varied from 1 to $9{ }^{\circ} \mathrm{C}$ in different bins of ice water path, with slightly larger differences in the daytime than in the nighttime. Such differences are statistically significant as indicated by the student $\mathrm{t}$-test, except for large IWP bins $\left(>225 \mathrm{~g} \mathrm{~m}^{-2}\right)$ in which CET approaches the threshold $\left(-38^{\circ} \mathrm{C}\right)$ of the homogenous nucleation process that is not controlled by the IN concentration.

The ice particle size of clouds also influences cloud emissivity and thus affects OLR, particularly for small IWP clouds where cloud emissivities are small (less than 1). Retrieved effective diameters of ice clouds in the daytime are smaller in the dust period than in the dust-free period. This is consistent with the recent satellite observation study by Ou et al. (2009). More ice nuclei introduced by a large concentration of mineral dusts produce more ice particles at warmer temperatures and lower supersaturation. Water vapor competition among numerous ice particles limits their growth, resulting in the relatively small sizes of ice particles. However, the relationship of effective diameters between the DS and DF periods is clearly reversed in the nighttime, except for two small IWP bins. Similar phenomena were reported by Lohmann et al. (2004) from a modeling study and by Chylek et al. (2006) based on satellite observation. Also, 

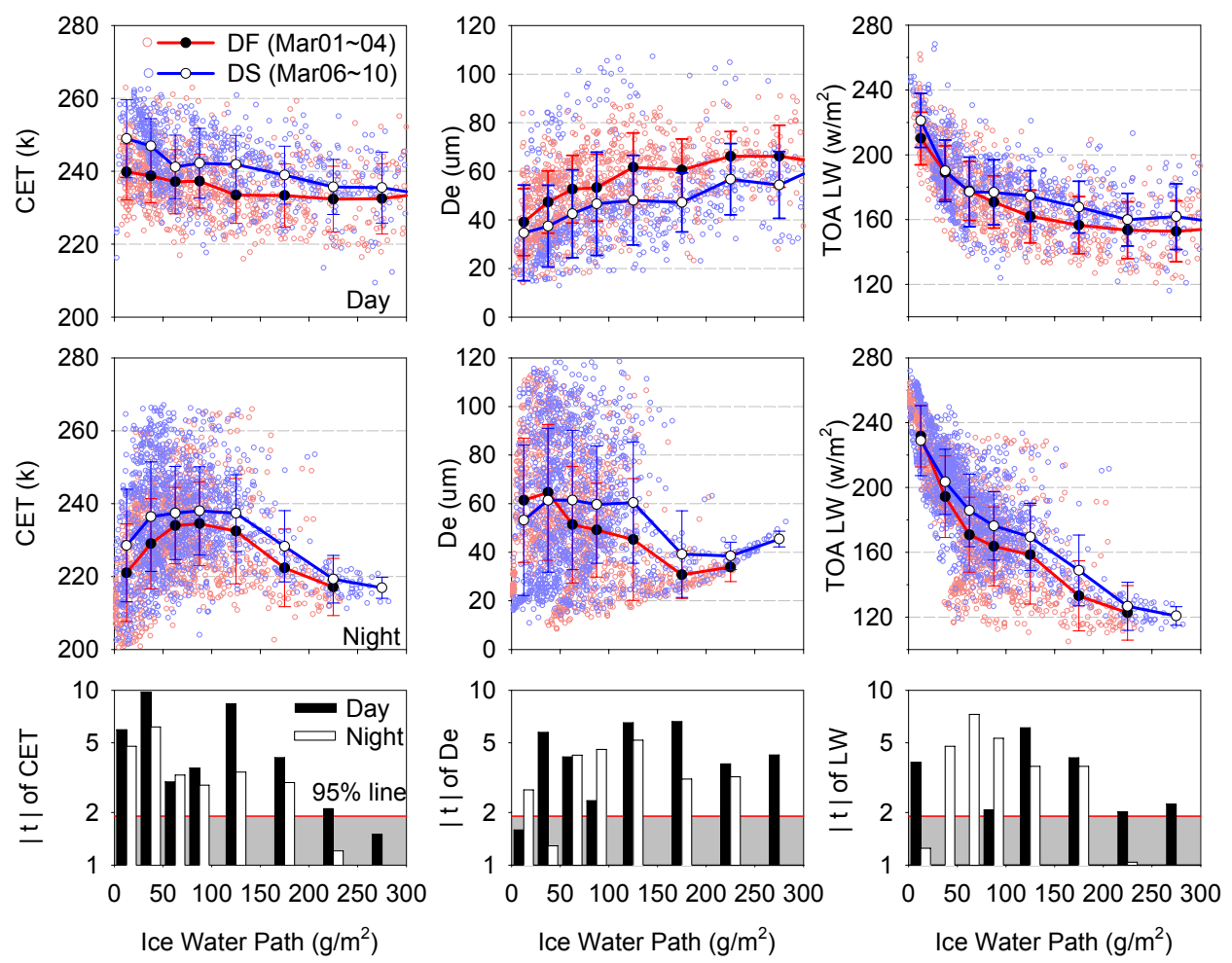

Fig. 4. FM3 and FM4 CERES observed/retrieved cloud effective temperature (CET, left panel), ice effective diameter (De, central panel) and upward longwave radiation flux (TOA LW, right panel) against ice water path (IWP) during day time (upper row) and nighttime (mid row). The $t$-test of difference of each parameter at given IWP between dust free (DF) and dust (DS) conditions are shown in the bottom row.

the nighttime cloud retrievals, which are based on all infrared channels, may have large uncertainties in inferred ice cloud water path and effective diameter. The reason for the larger effective size during the dust period in the nighttime, however, warrants further investigation.

The observed mean OLR decreases with IWP from $220 \mathrm{Wm}^{-2}$ to $120 \mathrm{Wm}^{-2}$ (soild lines in Fig. 4). The OLRs in the DS period for both daytime and nighttime passes were substantially higher than that in the DF period. Indirect effects of mineral dusts result in an enhancement of OLR from $4 \mathrm{Wm}^{-2}$ to $16 \mathrm{Wm}^{-2}$ for IWP between 87.5 and $275 \mathrm{~g} \mathrm{~m}^{-2}$. Those differences are substantially above the stability and absolute accuracy of $0.2 \%$ and $0.5 \%$ of CERES measurements, respectively (Wielicki et al. 1996). The student t-test further indicates the differences are statistically significant. It is evident that macrophysical changes in clouds exert a strong cooling effect by thermal infrared radiation on the cloud system. For the first three small IWP bins (IWP $<62.5 \mathrm{~g} \mathrm{~m}^{-2}$ ), however, the differences between the two are small or even negative.

There are two competitive indirect effects for clouds with small ice water path: the cooling effect due to cloud top changes as a consequence of heterogeneous nucleation, and the warming effect due to microphysical changes as mineral dust reducing ice particle size (The OLR can decrease with decreasing ice effective diameter, see Fig. 6c). The warming effect only exists for optically thin clouds where cloud emissivity is relatively small. Hence, in this case the enhancement of OLR associated with cloud macrophysical change in the DS period is compensated for by changes in cloud emissivity as a consequence of the dust-induced microphysical changes. It is also evident that the enhancement of OLR was more significant in the nighttime than in the daytime.

Various factors could influence OLR, such as cloud effective temperature (or height), ice water path, ice particle size, sea surface temperature, water vapor amount and profile, and another layer of cloud or dust aerosol below the ice cloud. A sensitivity study was conducted using a radiation model (Fu and Liou, 1992) and retrieved cloud properties to understand those factors on OLR. As shown in Fig. 5a, a change of $60 \%$ in atmospheric water vapor will result in a change of about $15 \mathrm{Wm}^{-2}$ on OLR under clear-sky conditions. Such changes will be dramatically reduced under cloudy conditions (Figures $5 b-5 c$ ). Since most water vapor is located below the ice cloud layer, the cloud layer blocks the thermal radiation emitted from the atmosphere below the clouds. There is no difference when the ice cloud is thick enough to be a blackbody. Measurements from AIRS/AMSU/HSB indicate that air temperature and relative humidity at the dust layer (1$3 \mathrm{~km}$ ) is about 0.5 degrees warmer and $20 \%$ drier than in the 

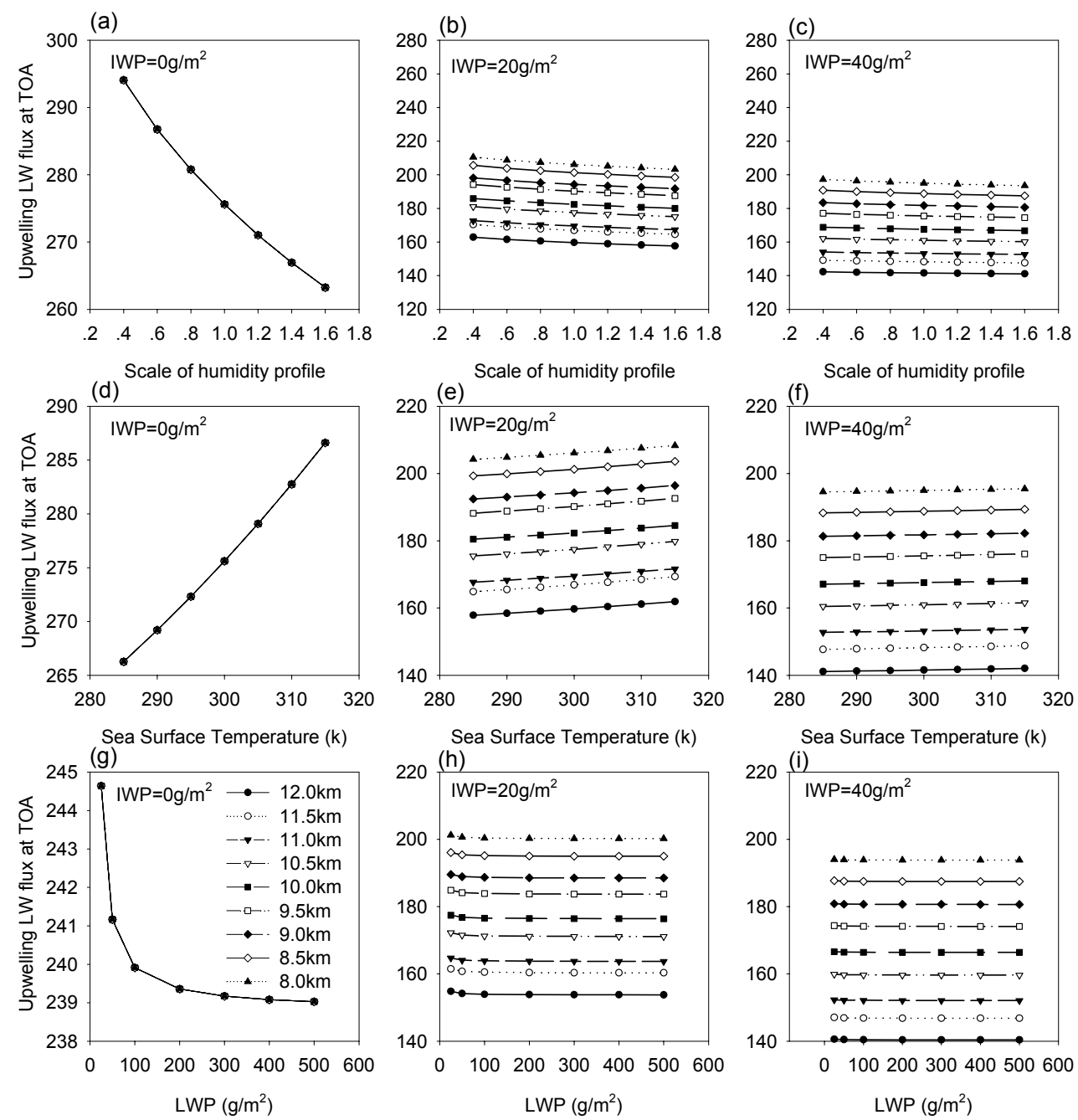

Fig. 5. Simulated OLR as functions of (a-c) changing relative humidity profiles with the ratio of 0.4-1.6 (shown in the $x$-axis) to the control one, (d-f) changing sea surface temperature from 285 to $315 \mathrm{~K}$, and (g-i) changing LWP from 20 to $500 \mathrm{~g} \mathrm{~m}^{-2}$ of the second cloud layer. Clouds with different IWPs $\left(0,20\right.$, and $40 \mathrm{~g} / \mathrm{m}^{2}$, from left to right) and different cloud top temperatures (different symbols, see Fig. $\left.5 \mathrm{~g}\right)$ are tested.

dust-free atmosphere, which will result in a change of about $5 \mathrm{Wm}^{-2}$ on OLR in the clear-sky but has a minor impact $\left(<1 \mathrm{Wm}^{-2}\right)$ when cloud IWP is larger than $40 \mathrm{~g} \mathrm{~m}^{-2}$.

Similarly, sea surface temperature has significant impacts on OLR under clear-sky conditions (Figures 5d). With increasing cloud IWP, the longwave emission from the sea surface will be increasingly blocked by the cloud (Fig. 5e-5f). A thin ice cloud with IWP of about $40 \mathrm{~g} \mathrm{~m}^{-2}$ would sufficiently block the sea surface emission, resulting in a negligible difference of OLR for different sea surface temperatures.

For a deep convective cloud system, multi-layer clouds often occur. To simulate this scenario, we add a layer of liquid cloud below the ice cloud, with cloud thickness of $1 \mathrm{~km}$ and cloud top height at $4.5 \mathrm{~km}$. We further assume the effective radius of the liquid cloud is $10 \mu \mathrm{m}$ and the cloud liquid water path varies from $25 \sim 500 \mathrm{~g} \mathrm{~m}^{-2}$. As shown in Fig. $5 \mathrm{~g}-\mathrm{i}$, the sensitivity of OLR to the second layer cloud is similar to the case with changes in sea surface temperature. With increasing IWP of the ice cloud, the changes in longwave emission from the second cloud layer will be increasingly blocked by the ice cloud. The difference of OLR is negligibly small if the upper ice cloud has IWP greater than $40 \mathrm{~g} \mathrm{~m}^{-2}$.

Overall, the sensitivity study demonstrates that the cloud effective temperature is a major controlling factor on observed OLR and ice particle size plays a minor role in modulating OLR when ice water path is small. When the ice clouds are optically thick enough, IWP $>40 \mathrm{~g} \mathrm{~m}^{-2}$, the OLR is insensitive to the changes of atmospheric conditions, such as sea surface temperature and/or another layer of cloud (or aerosol), below the ice clouds.

Simulated OLR using retrieved cloud effective temperature distribution and ice effective diameter information for a 

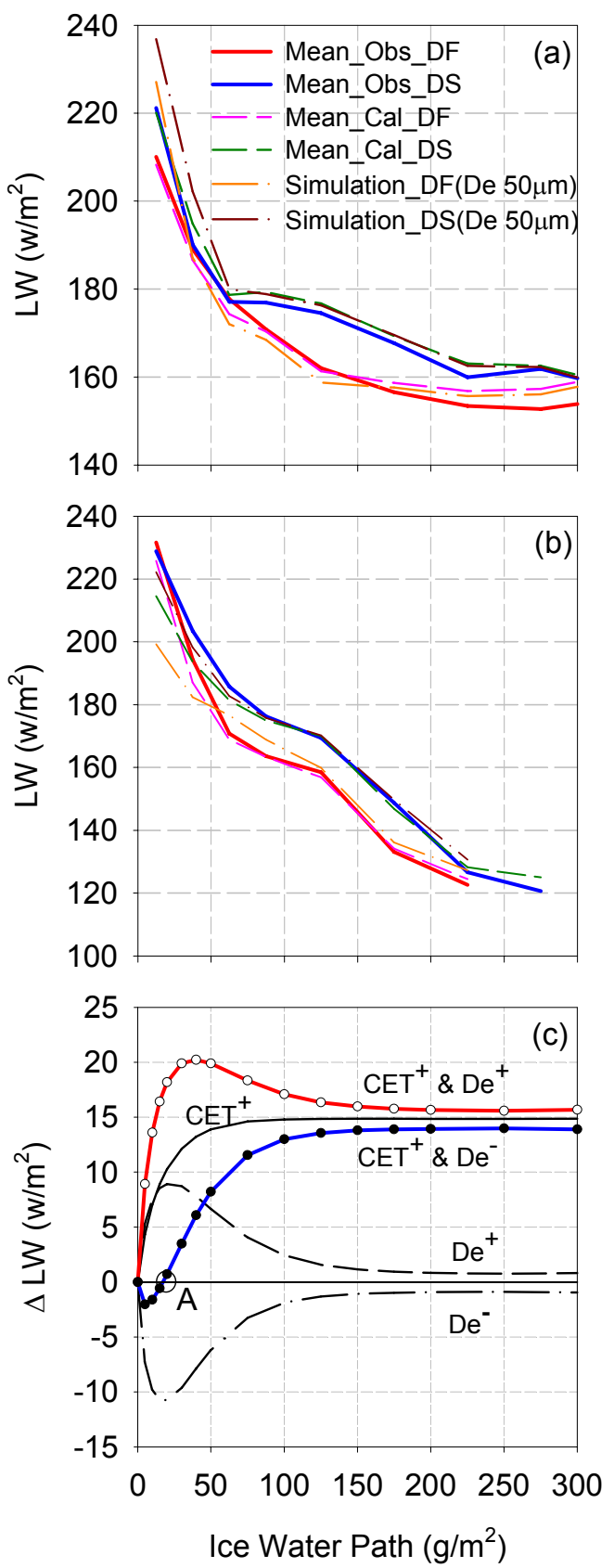

Fig. 6. Comparison of observed upward TOA long wave flux with: 1) that calculated employing both cloud effective temperature and ice effective diameter retrievals; 2 ) that simulated using cloud effective temperature distribution function without taking into account size impacts during (a) daytime and (b) nighttime. (c) A conceptional explanation of the impacts of cloud effective temperature (CET) and ice effective diameter (De) on upward TOA long wave flux. The control run was made at CET $-40^{\circ}$ and De $50 \mu \mathrm{m}$. Other calculations under warmer CET $(\mathrm{CET}+$, at cloud effective height $1 \mathrm{~km}$ lower), larger De (De+, $70 \mu \mathrm{m})$, smaller De (De-,30 $\mu \mathrm{m})$, and combinations of changes of CET and De (CET+ and De+; CET+ and De-) were made, respectively. Curves shown here are the differences between these calculations and the control. given IWP, shown in Fig. 6, compares well with the observed OLR. Simulation with variable CET but fixed particle diameter of $50 \mu \mathrm{m}$ captures the main variation of OLR in both dust and dust-free periods, except for the small IWP bins where the cloud layer is too thin to be a blackbody. In this optically thin regime, cloud emissivity is strongly sensitive to cloud particle size. For a given IWP, clouds with smaller particle size have larger emissivity and exert a warm effect on the cloud system. The combined effects, as shown in Fig. 6c, are consistent with the observed indirect effects of mineral dusts on OLR: scenarios with a warmer cloud effective temperature and a reduced effective diameter mimics well the daytime observations while scenarios with a warmer CET and an enhanced effective diameter imitate the nighttime observations. It indicates that these two factors are most important in determining OLR among other factors.

\section{Conclusion}

As one of the four major terrestrial sources of atmospheric aerosols (desert dust, biomass burning, biogenic and anthropogenic air pollution), mineral dust is responsible for significant climate forcing through the direct effect on extinction of solar and thermal radiation as well as the indirect effect on clouds and precipitation processes. Studies have suggested that a significant portion of the current atmospheric dust load originated from anthropogenic activities and mineral dust impacts on clouds have been observed even in the most remote region (Forster et al., 2007; Denman et al., 2007; Tegen and Fung 1995; Prospero 1999).

In this study, the combined measurements of MODIS and CERES consistently showed that the ice clouds over the Atlantic tend to be formed at warmer temperatures in the presence of mineral dusts. Our sensitivity study illustrated that such cloud effective temperature difference can not be explained simply by impacts of various dynamic and thermodynamic factors, including sea surface temperature, column integrated water vapor, convection available potential energy, air temperature difference between $850 \mathrm{hPa}$ and $500 \mathrm{hPa}$, vertical velocity and relative humidity at $500 \mathrm{hPa}$ (as well as at 850 and $300 \mathrm{hPa}$, not shown). Without in-situ measurements, it is hard to exclude completely all possible dynamic impacts. However, it is plausible that changes in nucleation processes of ice cloud due to mineral dust would result in substantial changes of cloud morphology, i.e., enhanced heterogeneous nucleation process results in more ice cloud formed at warmer temperatures. More importantly, the OLR flux associated with those clouds was much greater (up to $16 \mathrm{Wm}^{-2}$ ) under the dust conditions than that under dust-free conditions. Our radiative transfer modeling study confirmed that the enhancement of OLR is mainly due to a warmer cloud effective temperature. Induced changes of ice particle size by mineral dusts influence cloud emissivity and play a minor role in modulating OLR for optically thin ice clouds. 
It is also evident that the enhancement of OLR due to mineral dusts is more significant in the nighttime when solar heating is absent than in the daytime. Such a strong cooling forcing of thermal infrared radiation would have significant impacts on the cloud system and its evolution. This may also represent another possible mechanism by which anthropogenic activities are perturbing the climate. The actual climate response to the described radiation pathway of aerosol indirect effects remains to be evaluated.

Acknowledgements. This research was supported by the Office of Science (BER), US Department of Energy, Grant DE-FG0203ER63531, and by the NOAA Educational Partnership Program with Minority Serving Institutions (EPP/MSI) under cooperative agreements NA17AE1625 and NA17AE1623.

Edited by: G. Vaughan

\section{References}

Chylek, P., Dubey, M. K., Lohmann, U., Ramanathan, V., Kaufman, Y. J., Lesins, G., Hudson, J., Altmann, G., and Olsen, S.: Aerosol indirect effect over the Indian Ocean, Geophys. Res. Lett., 33, L06806, doi:10.1029/2005GL025397, 2006.

DeMott, P. J., D. C. Rogers, S. M. Kreidenweis, Y. Chen, C. H. Twohy, D. Baumgardner, A. J. Heymsfield, and K. R. Chan: The Role of Heterogeneous Freezing Nucleation in Upper Tropospheric Clouds: Inferences from SUCCESS, Geophys. Res. Lett., 25(9), 1387-1390, 1998.

DeMott P. J., D. J. Cziczo, A. J. Prenni, D. M. Murphy, S. M. Kreidenweis, D. S.Thomson, R. Borys, and D. C. Rogers (2003 a) Measurements of the concentration and composition of nuclei for cirrus formation, Proc. Natl. Acad. Sci.,, 100, 14655-14660.

DeMott, P. J., K. Sassen, M. R. Poellot, D. Baumgardner, D. C. Rogers, S. D. Brooks, A. J. Prenni, and S. M. Kreidenweis (2003), African dust aerosols as atmospheric ice nuclei, Geophys. Res. Lett., 30(14), 1732, doi:10.1029/2003GL017410.

Denman, K. L., Brasseur, G., Chidthaisong, A., et al.: Couplings Between Changes in the Climate System and Biogeochemistry in: Climate Change 2007: The Physical Science Basis. Contribution of Working Group I to the Fourth Assessment Report of the Intergovernmental Panel on ClimateChange , edited by: Solomon, S., Qin, D., Manning, M., Chen, Z., Marquis, M., Averyt, K. B., Tignor, M., and Miller, H. L., Cambridge University Press, Cambridge, UK and New York, NY, USA, 2007.

Forster, P., Ramaswamy, V., Artaxo, P., et al.: Changes in Atmospheric Constituents and in Radiative Forcing in: Climate Change 2007: The Physical Science Basis. Contribution of Working Group I to the Fourth Assessment Report of the Intergovernmental Panel on ClimateChange, edited by: Solomon, S., Qin, D., Manning, M., Chen, Z., Marquis, M., Averyt, K. B., Tignor, M., and Miller, H. L., Cambridge University Press, Cambridge, UK and New York, NY, USA, 2007.

$\mathrm{Fu}$, Q., Yang, P., and Sun, W. B.: An accurate parameterization of the infrared radiative properties of cirrus clouds for climate models, J. Climate, 11, 2223-2237, 1998.
$\mathrm{Fu}, \mathrm{Q} .:$ An accurate parameterization of the solar radiative properties of cirrus clouds for climate models, J. Climate, 9, 20582082, 1996.

Fu, Q. and Liou, K. N.: On the correlated k-distribution method for radiative transfer in nonhomogeneous atmospheres, J. Atmos. Sci., 49, 2139-2156, 1992.

Garrett, T. J. and Zhao, C.: Increased Arctic cloud longwave emissivity associated with pollution from mid-latitudes, Nature, 440 , 787-789, 2006.

Geier, E., Green, R., Kratz, D., Minnis, P., Miller, W., Nolan, S., and Franklin, C.: Clouds and the Earth's Radiant Energy System (CERES) data management system: Single satellite footprint TOA/surface fluxes and clouds (SSF) collection document. Release 2, version 1, NASA Langley Research Center, 212 pp. and appendixes, available online at: http://asd-www.larc.nasa.gov/ ceres/collect_guide/SSF_CG.pdf, 2003.

Gong, W., Min, Q., Li, R., Teller, A., Joseph, E., and Morris, V.: Detailed cloud resolving model simulations of the impacts of Saharan air layer dust on tropical deep convection - Part 1: Dust acts as ice nuclei, Atmos. Chem. Phys. Discuss., 10, 12907-12952, doi:10.5194/acpd-10-12907-2010, 2010.

Haywood, J. M. and Boucher, O.: Estimates of the direct and indirect radiative forcing due to tropospheric aerosols: A review. Rev. Geophys., 38, 513-543, 2000.

Hung, H. M., Malinowski, A., and Martin, S. T.: Kinetics of Heterogeneous Ice Nucleation on the Surfaces of Mineral Dust Cores Inserted into Aqueous Ammonium Sulfate Particles, J. Phys. Chem. A 107, 1296-1306, 2003.

King, M. D., Tsay, S.-C., Platnick, S. E., Wang, M., and Liou, K. L.: Cloud Retrieval Algorithms for MODIS: Optical Thickness, Effective Particle Radius, and Thermodynamic Phase, Products: 06_L2, 08_D3, 08_E3, 08_M3, ATBD Reference Number: ATBD-MOD-05, vailable online at: http://modis-atmos. gsfc.nasa.gov/_docs/atbd_mod05.pdf, 1998.

Levi, Y. and Rosenfeld, D.: Ice nuclei, rainwater chemical composition and static cloud seeding effects in Israel, J. Appl. Meteor., 35, 1494-1501, 1996.

Lohmann, U., Karcher, B., and Hendricks, J.: Sensitivity studies of cirrus clouds formed by heterogeneous freezing in the ECHAM GCM, J. Geophys. Res., 109, D16204, doi:10.1029/2004JD004811, 2004.

Lubin, D. and Vogelmann, M. A.:, Climatologically significant aerosol long wave indirect effect in the Arctic, Nature, 439, 453456, 2006.

Menzel W. P., R. A. Frey, B. A. Baum and H. Zhang (2006), Cloud Top Properties and Cloud Phase - Algorithm Theoretical Basis Document. Products: 06_L2, 08_D3, 08_E3, 08_M3. ATBD Reference Number: ATBD-MOD-04, available online at: http://modis-atmos.gsfc.nasa.gov/_docs/MOD06CT: MYD06CT_ATBD_C005.pdf

Min, Q.-L., Li, R., Lin, B., 5 Joseph, E., Wang, S., Hu, Y., Morris, V., and Chang, F.: Evidence of mineral dust altering cloud microphysics and precipitation, Atmos. Chem. Phys., 9, 3223 3231, doi:10.5194/acp-9-3223-2009, 2009.

Ou, S. S-C., Liou, K.-N., Wang, X., Hansell, R., Lefevre, R., and Cocks, S.: Satellite remote sensing of dust aerosol indirect effects on ice cloud formation, Appl. Optics, 48, 633-642, 2009.

Prospero, J. M.: Long-term measurements of the transport of African mineral dust to the southeastern United States: Impli- 
cations for regional air quality. J. Geophys. Res., 104, 1591715928, doi:10.1029/1999JD900072, 1999.

Rosenfeld, D., Rudich, Y., and Lahav, R.: Desert dust suppressing precipitation: A possible desertification feedback loop, Proc. Natl. Acad. Sci., 98, 5975-5980, 2001.

Rosenfeld D., Lohmann, U., Raga, G. B., O’Dowd, C. D., Kulmala, M., Fuzzi, S., Reissell, A., and Andreae, M. O.: Flood or Drought: How Do Aerosols Affect Precipitation?, Science, 321, 1309-1313, 2008.

Sassen K.: Dusty ice clouds over Alaska, Nature, 434, p. 456, 2005. Sassen, K., Demott, P. J., Prospero, J. M., and Poellet, M. R.: Saharan Dust storms and indirect aerosol effects on clouds: CRYSTAL-FACE Results. Geophys. Res. Lett., 30, 1633, doi:10.1029/2003GL017371, 2003.

Sassen, K.: Indirect climate forcing over the western US from Asian dust storms, Geophys. Res. Lett., 29, 1732, doi:10.1029/2001GL014051, 2002.

Schaller, R. C. and Fukuta, N.: Ice nucleation by aerosol particles: Experimental studies using a wedge-shaped ice thermal diffusion chamber, J. Atmos. Sci., 36, 1788-1802, 1979.
Sherwood, S. C., Minnis, P., and McGill, M.: Deep convective cloud top heights and their thermodynamic control during CRYSTAL-FACE, J. Geophys. Res., 109, D20119, doi:10.1029/2004JD004811, 2004.

Tegen, I. and Fung, I.: Contribution to the atmospheric mineral aerosol load from land surface modifi cation. J. Geophys. Res., 100, 18707-18726, 1995.

Toon B. O.: African dust in Florida clouds, Nature, 424, 623-624, 2003

Twomey, S.: The influence of pollution on the shortwave albedo of clouds, J. Atmos. Sci., 34, 1149-1152, 1977.

van den Heever, S. C., Carrió, G. G., Cotton, W. R., DeMott, P. J., and Prenni, A. J.: Impacts of Nucleating Aerosol on Florida Storms, Part I: Mesoscale Simulations, J. Atmos. Sci., 63(7), 1752-1775, 2006.

Wielicki, B. A., Barkstrom, B. R., Harrison, E. F., Lee, R. B., Louis Smith, G., and Cooper, J. E.: Clouds and the Earth's Radiant Energy System (CERES): An Earth Observing System Experiment, Bull. Amer. Meteor. Soc., 77, 853-868, 1996. 